\section{Estudo \\ Ecidebate}

em Testão

Dlanejamento
Revista Estudo \& Debate, Lajeado, v. 26, n. 4, 2019. ISSN 1983-036X

DOI: http://dx.doi.org/10.22410/issn.1983-036X.v26i4a2019.2170

\title{
O PERFIL DOS CONSUMIDORES DE PRODUTOS ORGÂNICOS DA CIDADE DE SANTA MARIA-RS
}

\author{
Natália Heinze Pohl ${ }^{1}$, João Batista Corrêa Pereira Filho², Eduardo Botti Abbade ${ }^{3}$
}

\begin{abstract}
Resumo: Produtos orgânicos adquiriram grande atençấo dos mercados e da sociedade, pois o mercado e a demanda por produtos orgânicos vêm crescendo de forma significativa em todo o mundo. Este estudo teve como objetivo analisar o perfil demográfico e comportamental do consumidor de produtos orgânicos. Foi realizado um estudo de levantamento por meio de uma pesquisa de campo com aplicaçáo de questionário com uma amostra por adesão de 206 respondentes. Após a coleta, os dados obtidos foram tabulados e posteriormente analisados com o auxílio do software Excel. O estudo encontrou um perfil de consumidores de alimentos orgânicos de maioria do gênero feminino, com alta escolaridade, solteiro e sem filhos. A preocupação com a saúde é o principal motivo para o consumo de orgânicos, mas a maioria não tem total confiança de que os alimentos que compram como orgânicos o sejam totalmente orgânicos. Os respondentes que não consomem orgânicos afirmam como principal motivo a falta de acesso, o que mostra que há uma demanda no mercado por esses produtos, cuja oferta é muito baixa em relaçáo ao alimento convencional.
\end{abstract}

Palavras-chave: marketing; comportamento do consumidor; alimentos orgânicos; preocupação com a saúde; certificação de orgânicos.

\section{THE PROFILE OF CONSUMERS OF ORGANIC PRODUCTS OF THE CITY OF SANTA MARIA-RS}

\begin{abstract}
Organic products have acquired great attention from markets and the society, as the market and the demand for organic products have grown significantly in the world. This study aimed to analyse the demographical and behavioral profiles of consumer of organic products. A survey was carried out through a field survey with questionnaire application in a convenience sample of 206 respondents. After the data collection, the data were tabulated and later analyzed with the help of Excel software. The study found a profile of organic foods consumers of mostly female, high school, single and childless. The concern about health is the main reason for organic consumption, but most do not have full confidence that the "organic foods" they are purchasing are really organic. Respondents who do not consume organic say as main reason the lack of access, which shows that there is a demand in the market for these products, whose supply is very low compared to conventional food.
\end{abstract}

Keywords: marketing; consumer behavior; organic food; concern for health; certification.

1 Bacharel em Administração pela Universidade Franciscana (UFN).

2 Acadêmico do Curso de Administração da Universidade Federal de Santa Maria (UFSM).

3 Professor do Departamento de Ciências Administrativas da Universidade Federal de Santa Maria (UFSM). 


\section{Introduçáo}

O estudo do comportamento do consumidor tornou-se um alicerce no processo de elaboração de estratégias mercadológicas que atendam às necessidades, desejos e expectativas de seus clientes. Para Engel, Blackwell e Miniard (2000) o estudo do mercado deve ser um exercício permanente das organizaçóes, observando as atitudes e comportamentos dos seus compradores.

Lombardi, Moori e Sato (2004), identificaram em seu estudo que a demanda no mercado de orgânicos é crescente, sendo o alcance de larga escala produtiva com preço competitivo um fator crítico para o sucesso desse segmento. Barbosa et al. (2011) constataram que o fator saúde é o principal fator motivador para a compra de orgânicos, seguido pela não utilização de agrotóxicos e conservação do meio ambiente. Os fatores limitantes para a compra de orgânicos são os preços mais elevados do que os produtos convencionais seguido da baixa disponibilidade de produtos.

Dentro do contexto de mercado de orgânicos, Araújo, Paiva e Filgueira (2007) trazem que o acesso cada vez mais facilitado a informaçóes por parte dos consumidores e a ampliação de mercados mais flexíveis, está formando um consumidor muito mais exigente e consciente em relação à escolha e compra dos produtos alimentícios, surgindo assim, um novo tipo de consumidor, chamado "consumidor orgânico".

Neste contexto, o presente trabalho tem objetivo identificar o perfil do consumidor de produtos orgânicos da cidade de Santa Maria/RS. Este estudo se justifica devido à relevância do estudo do comportamento do consumidor para as organizaçóes, pois este viabiliza um processo de elaboração de estratégias eficientes. De acordo com Engel, Blackwell e Miniard (2000), nos últimos 30 anos, houve o surgimento de um crescente campo multidisciplinar de pesquisa sobre a motivação e o comportamento do consumidor, sendo esta de importância essencial.

Logo, compreender os fatores que influenciam no processo de decisão de compra de um cliente, é informação de suma importância para as organizações que buscam a satisfação plena das necessidades, desejos e expectativas dos seus consumidores. Com os consumidores de produtos orgânicos, por exemplo, esse processo não é diferente, é notório que existe uma preocupação por parte das empresas em compreender seus principais anseios. De acordo com Darolt (2002), o mercado e a demanda por produtos orgânicos vêm crescendo de forma significativa, em todo o mundo, logo buscar compreender este segmento é essencial às empresas que atendem esse público.

No Brasil, não há levantamentos sistematizados de dados sobre a produção de produtos orgânicos no país, conforme nos trazem Santos e Monteiro (2004), o que mostra a relevância do estudo deste tema, bem como do comportamento dos seus consumidores, constituindo uma área carente de pesquisas dentro dos orgânicos, o que impossibilita que as empresas criem estratégias eficientes para atingir esse público-alvo.

\section{Comportamento do consumidor}

Sheth, Mittal e Newman (2001, p. 29) definem comportamento do consumidor como "as atividades físicas e mentais realizadas por clientes de bens de consumo e industriais que 
resultam em decisōes e ações, como comprar e utilizar produtos e serviços, bem como pagar por eles". Nesse sentido, Engel, Blackwell e Miniard (2000, p. 4) definem comportamento do consumidor como "atividades diretamente envolvidas em obter, consumir e dispor de produtos e serviços, incluindo os processos decisórios que antecedem e sucedem estas açóes".

Samara e Morsch (2005) afirmam que entender o comportamento do consumidor não é tarefa fácil, pois há uma complexidade que cerca o comportamento humano e esse estudo envolve diversas áreas do conhecimento. Schiffman e Kanuk (2000) dizem que o comportamento do consumidor é um estudo de como os indivíduos tomam as decisóes de gastar seus recursos disponíveis em produtos relacionados ao seu consumo.

Saber quem é o consumidor bem como a reação dele aos estímulos presentes no momento da compra é fundamental na busca incessante da compreensão dos consumidores (IBDAIWI, 2009). Samara e Morsch $(2005$, p. 2) afirmam que "analisar e compreender os diversos fatores que influenciam as pessoas em suas decisōes de compra é, pois, atividade desafiadora para os profissionais de marketing".

É fato que há muitos meios de influenciar no comportamento do consumidor, sabe-se também da diferença dessas influências sobre cada tipo de produto e público-alvo. Logo, não se podem levar em consideração as inúmeras possibilidades de cada situação, mas existem os chamados princípios comportamentais gerais, que são utilizados para um maior conhecimento sobre o público-alvo (MATTEI; MACHADO; OLIVEIRA, 2006).

Samara e Morsch (2005) dizem que frequentemente consumidores respondem a influências externas e interpessoais, decidindo suas compras baseados no que acreditam que projetará imagens favoráveis aos demais e que atenderão as expectativas que os outros esperam dele. Para Churchill e Peter (2012) são muitas as variáveis que afetam o comportamento do consumidor.

\subsection{Comportamento do consumidor de produtos orgânicos}

O produto orgânico é definido como um bem agroalimentar especial, que tem como características básicas a ausência de agrotóxicos e fertilizantes em seu cultivo. É considerado um alimento saudável, sendo que todo seu processo produtivo envolve normas específicas, que se destinam à preservaçáo dos recursos naturais e visam à satisfação entre produtores, trabalhadores rurais e consumidores nas suas relaçôes econômicas e sociais (MIRANDA, 2001; ZUIN; QUEIROZ, 2006).

Devido às características específicas dos produtos orgânicos, à grande disseminação de informações ambientais e à efervescência ecológica como movimento global, especialmente a partir da década de 90, a demanda por produtos orgânicos cresceu acentuadamente, bem como a conscientização dos consumidores acerca destes produtos e o pensamento crítico dos mesmos no processo de compra (RUCINSKI; BRADENBURG, 2002).

O mercado de orgânicos apresenta uma demanda crescente no Brasil. Dentre os fatores responsáveis por esse aumento de demanda, existem cinco que podem ser considerados: preocupação dos consumidores com a saúde e ingestão de resíduos agrotóxicos, aumento da atuação de ONGs preocupadas com o meio ambiente, influência de seitas religiosas que prezam a ingestáo de alimentos saudáveis para o equilíbrio espiritual e harmonia com a 
natureza, luta de grupos contra o domínio de grandes corporações transnacionais sobre a agricultura e utilização pelas grandes redes de supermercados de ferramentas de marketing para a indução da demanda por orgânicos, devido à influência dos países desenvolvidos (CAMPANHOLA; VALARINI, 2001).

Os consumidores de produtos orgânicos podem ser classificados em dois grupos, segundo Buainain e Batalha (2007), sendo o primeiro formado por indivíduos bem informados e exigentes quanto à qualidade do produto, normalmente consumidores mais antigos que frequentam as feiras verdes de produtos orgânicos. Já o segundo grupo, é formado pelos consumidores das grandes redes de supermercados, sendo mais recente e pouco estudado.

Em contrapartida, Coelho (2001) afirma que os consumidores de orgânicos são profissionais liberais, acadêmicos, executivos e estudantes e classificam-se em quatro categorias. Tais categorias são descritas como sendo as seguintes:

[...] os politicamente ou ideologicamente motivados, que consomem produtos orgânicos para proteger o meio ambiente; os motivados por questóes de saúde, que consomem produtos orgânicos porque esses produtos não contêm agrotóxicos, hormônios, antibióticos etc.; os que consomem um mix de produtos convencionais e orgânicos e os que consomem apenas temporariamente, em função de influência momentânea da mídia (COELHO, 2001, p.10).

Ormond et al. (2002) observa que o principal valor dos orgânicos para os seus consumidores é a confiança, sendo que o que leva os mesmos a preferi-los em detrimento dos alimentos convencionais é a ausência de toxicidade, a informação sobre suas vantagens nutricionais e a confiança de que foram produzidos conforme as normas de certificação.

Conforme pesquisa realizada por Sampaio et al. (2013), que analisou a produção acadêmica no Brasil sobre o comportamento do consumidor de alimentos orgânicos no período entre 1997 a 2011, diversos autores verificaram que o consumo de produtos orgânicos tem um simbolismo ecológico, que leva à uma atitude preservação do meio ambiente, bem como mudanças que vão além do comportamento alimentar.

Em estudo conduzido em um supermercado de Sáo Paulo, evidenciou-se que os motivos que levam os consumidores abordados a comprarem alimentos orgânicos são a qualidade e os benefícios que agregam à saúde (BRAGA JUNIOR; NETO; MORAES, 2014). Já em outro estudo conduzido em Florianópolis/SC evidenciou-se que também a preocupação com a saúde é o fator mais relevante que motiva as pessoas a escolherem alimentos orgânicos (KRISCHKE; TOMIELLO, 2009).

Foi constatado, em estudo realizado por Pereira et al. (2015) em Pelotas/RS, que as motivaçóes que influenciam a compra de alimentos orgânicos são muito diversas, sendo que os consumidores com menor nível de escolaridade e renda começaram a frequentar mais as feiras agroecológicas passando a consumir mais alimentos orgânicos, bem como contatou-se que todos os consumidores estavam preocupados com saúde e alimentação, sendo pequena a parcela dos que apresentavam diagnóstico de doença. 
De acordo com Brandão (2016), a preocupação com a saúde e com a segurança alimentar, são duas variáveis que contribuem de forma significativa para a formação de atitudes favoráveis à compra de alimentos orgânicos e que esta, por sua vez, tem influência na intenção de compra das pessoas. Atitudes positivas também acabam influenciando na disposição a pagar mais por alimentos saudáveis. Buzin (2016), em pesquisa realizada em Goiânia/GO, destaca que tanto os consumidores de alimentos orgânicos quanto os consumidores de alimentos convencionais, afirmaram não encontrar produtos orgânicos com facilidade e apontam a incompletude da cadeia produtiva de alimentos orgânicos, visto que em função das dificuldades de encontrar este tipo de alimento em locais de venda existe um grupo de consumidores que não é atendido.

\section{Material e método}

A presente pesquisa, quanto à sua natureza, classificou-se como quantitativa. Conforme Pinheiro (2006, p. 89) a pesquisa quantitativa é "um estudo estatístico que se destina a descrever as características de uma determinada situação mercadológica, medindo numericamente as hipóteses levantadas a respeito de um problema de pesquisa". Para Zikmund (2006) o objetivo da pesquisa quantitativa é a determinação da extensão ou da quantidade de determinados fenômenos em forma de números.

Quanto aos objetivos do trabalho, este foi de natureza descritiva. De acordo com Zikmund (2006) a pesquisa descritiva é usada de maneira frequente para descobrir a natureza de compra ou de algum outro comportamento do consumidor, de modo a atender ao problema de pesquisa inicial. Gil (2002) afirma que a pesquisa descritiva tem como objetivo descrever as características de uma determinada população ou fenômeno, bem como o estabelecimento de relaçóes entre variáveis. Para Cervo e Bervian (1996, p. 49) a pesquisa descritiva "observa, analisa e correlaciona fatos ou fenômenos (variáveis) sem manipulá-los".

Este estudo contou com o método de estudo de levantamento (survey), que de acordo com Babbie (1999, p. 78) "surveys são semelhantes a censos, sendo a diferença principal entre eles é que um survey, tipicamente, examina uma amostra de população, enquanto o censo implica enumeração de uma população toda". Também se considera que este estudo é um estudo de campo. De acordo com Siqueira (2013), o estudo de campo é aquele que busca os dados em um determinado campo social de determinada situação cultural e faixa etária, utilizando-se do testemunho de pessoas com o objetivo de registrar e observar o fato ou fenômeno a ser estudado e sentir o mesmo de maneira mais próxima.

O instrumento de coleta de dados utilizado no presente trabalho foi um questionário elaborado pelos autores do estudo, contendo 13 questóes no total. Dessas, 2 foram questóes em escala de 1 a 5 , e as outras 11 foram questóes de múltipla escolha, sendo 6 destas relacionadas ao perfil do respondente. O questionário foi pré-testado de modo a ser validado por eio de uma aplicação com uma amostra piloto de 10 respondentes representantes da população do estudo. Pequenos ajustes de escrita e termos técnicos foram realizados na versão final do instrumento. Segundo Markoni e Lakatos (2010), a coleta de dados configura-se como a etapa da pesquisa em que a aplicação dos instrumentos elaborados e das técnicas selecionadas é iniciada, de modo a realizar a coleta dos dados previstos. Michel (2005, p. 46) 
afirma que "o questionário é constituído por uma série ordenada de perguntas, que devem ser respondidas por escrito e sem a presença do entrevistador".

De acordo com o site do IBGE (2016), a cidade de Santa Maria-RS possui uma população de 261.031 habitantes. O cálculo da amostra da presente pesquisa, foi realizado através da fórmula do cálculo amostral de Santos (2016), como mostra a equação 1 a seguir:

$$
n=\frac{N \cdot Z^{2} \cdot p \cdot(1-p)}{Z^{2} \cdot p \cdot(1-p)+e^{2} \cdot(N-1)}
$$

Onde:

n - amostra calculada

$\mathrm{N}$ - população

Z - variável normal padronizada associada ao nível de confiança

p - verdadeira probabilidade do evento

e - erro amostral

Obteve-se a adesão de 206 respondentes com respostas válidas ao questionário aplicado. Isso sugere que, a partir do cálculo realizado por meio da equação acima, que a amostra possui uma margem de erro de $+/-7 \%$ e nível de significância de $95 \%$. Assim, considera-se que tal amostra é representativa e possibilita a inferência estatística.

Os dados coletados no questionário aplicado para a amostra obtida foram tabulados e analisados com o auxílio do software Excel. Ademais, os resultados foram analisados e confrontados com a literatura, obtendo-se assim as respostas pertinentes ao problema de pesquisa.

\section{Resultados do estudo}

A seguir serão abordados os resultados coletados na aplicação dos questionários para o alcance do objetivo do presente estudo, o qual consistiu em identificar o perfil do consumidor de produtos orgânicos da cidade de Santa Maria/RS. O presente tópico é dividido em duas partes. A primeira parte expóe os resultados acerca do perfil dos respondentes. A segunda parte deste tópico irá apresentar os resultados específicos do estudo, acerca do comportamento e opiniáo dos respondentes sobre o consumo de alimentos orgânicos.

\subsection{Perfil dos respondentes}

Para traçar o perfil dos respondentes, foram levadas em consideração as seguintes variáveis: idade, gênero, escolaridade, estado civil, se possuem filhos ou não e a renda bruta familiar. A média da idade dos respondentes foi de 31,64 anos, considerando a quantia de 201 respondentes com respostas válidas. Observou-se ainda que a maior idade registrada foi 70 anos e a menor idade registrada foi 18 anos.

Quanto ao gênero, foram obtidas 206 respostas válidas e percebe-se uma grande diferença no percentual dos respondentes do gênero feminino e masculino, 64, 1\% e 35,9\% respectivamente. Em relação à escolaridade, considerando as 206 respostas válidas, 35,4\% 
afirmam possuir ensino superior incompleto, $31,1 \%$ possuem a pós-graduação, $26,7 \%$ possuem ensino superior completo, $6,3 \%$ possuem o ensino médio completo e apenas $0,5 \%$ possuem apenas até o ensino fundamental completo.

O estado civil dos respondentes (205 respostas válidas), mostra que a maioria é solteiro(a) (68,3\%), enquanto $24,9 \%$ afirmam ser casado(as), 6,3\% divorciado(as) e apenas $0,5 \%$ viúvo(a). Além disso, um dado bastante relevante é que $76,7 \%$ dos respondentes não possuem filhos e apenas 23,3\% possuem (206 respostas válidas).

\subsection{Resultados específicos do estudo}

Nesta sessão, são exibidos os resultados específicos da coleta de dados do presente estudo, onde buscou-se evidenciar o comportamento dos consumidores de produtos orgânicos de Santa Maria/RS em relação à opinião e consumo de alimentos orgânicos. Para isso, foram elaboradas 7 questóes, que serão analisadas uma a uma, fazendo relação com outros estudos sobre alimentos orgânicos. A Figura 1, a seguir, mostra o nível de consumo dos respondentes de alimentos classificados como orgânicos.

Figura 1 - Nível de consumo dos respondentes de alimentos classificados como orgânicos

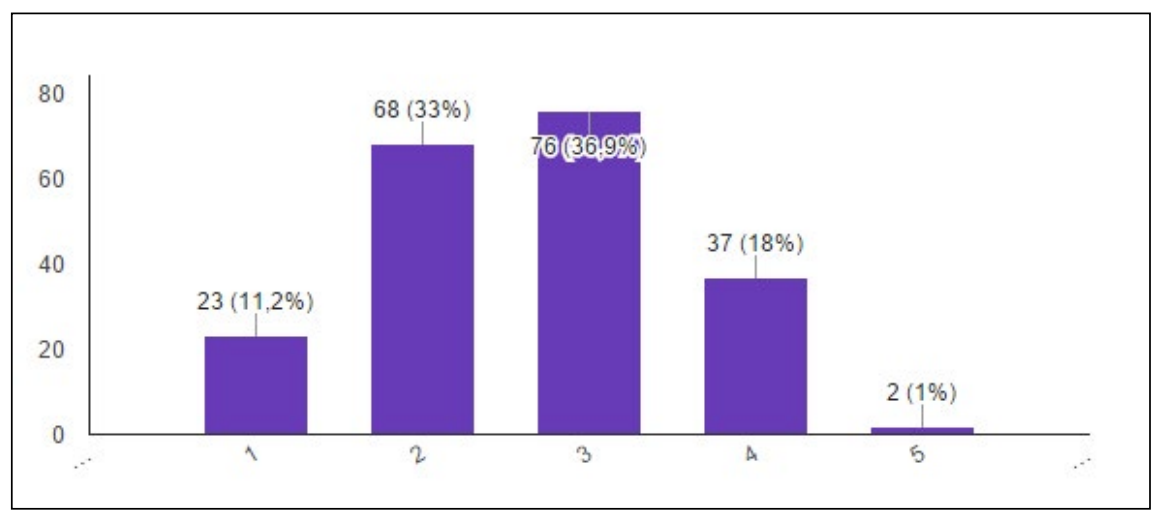

Nota: Esta questáo foi mensurada por meio de escala Likert de 5 pontos, indo de 1 (Nunca consumo alimentos orgânicos [0\% orgânico]) até 5 (Apenas consumo alimentos orgânicos [100\% orgânico]). Foram obtidas 206 respostas válidas.

A Figura 1 mostra que a grande maioria dos pesquisados (36,9\%) está em uma categoria intermediária de consumo de alimentos de orgânicos, não sendo sua alimentação composta $100 \%$ por alimentos orgânicos, nem $100 \%$ por alimentos convencionais. O consumo de alimentação $100 \%$ orgânica é inexpressivo (1\%), no entanto, $88,8 \%$ do total dos respondentes afirmaram consumir alimentos orgânicos em algum nível em sua alimentação.

No estudo de Lombardi et al. (2004), foi verificado que os consumidores mostraramse favoráveis e crescentes em relação ao consumo de produtos orgânicos, mesmo não conhecendo exatamente as diferenças do processo de produção, havendo forte inclinação para o que é alimento natural, manifestada através do consumo de alimentos orgânicos. 
Pode-se, através dos resultados encontrados na Figura 1, evidenciar este mesmo processo nos resultados encontrados no presente estudo.

Em sua pesquisa, Rucinski e Bradenburg, (2002), com base nos dados relacionados com a frequência da demanda, verificaram que $58,8 \%$ dos pesquisados frequentam a feira 1 vez por semana e $25,5 \%$ duas vezes por mês. A investigação também indica que $88,2 \%$ dos consumidores são adeptos permanentes da alimentação orgânica, e 11,8\% dos entrevistados consomem ocasionalmente esses produtos.

$\mathrm{Na}$ Figura 2, abaixo, estáo os locais em que os respondentes que consomem orgânicos adquirem estes produtos.

Figura 2 - Locais em que os respondentes que consomem orgânicos adquirem estes produtos

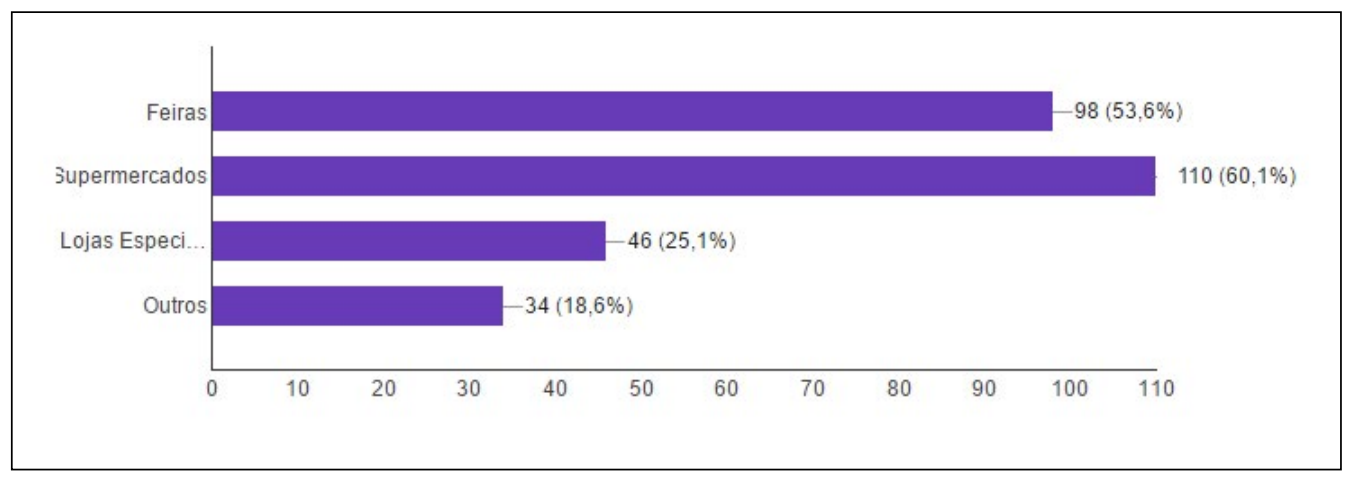

Nota: Esta questão foi mensurada por meio de questão de múltipla escolha, sendo que os respondentes podiam marcar mais de uma questáo referente ao local de compra dos produtos orgânicos. Foram obtidas 183 respostas válidas.

A partir da análise da Figura 2, verifica-se que os locais em que os respondentes adquirem produtos orgânicos, são, em sua maioria supermercados $(60,1 \%)$ e feiras $(53,6 \%)$, seguido de lojas especializadas $(25,1 \%)$ e outros estabelecimentos ou locais $(18,6 \%)$. Buzin (2016), mostra em seu estudo que os consumidores entrevistados informaram que o supermercado é o principal local escolhido para compras de hortaliças e frutas como alternativa às feiras livres. Conforme os resultados do presente estudo corrobora-se a opçáo dos consumidores pelos supermercados e feiras como locais de principal consumo de alimentos orgânicos na cidade de Santa Maria/RS.

A Figura 3, a seguir, apresenta os produtos orgânicos que os respondentes consomem com mais frequência. 
Figura 3 - Produtos orgânicos que os respondentes consomem com mais frequência

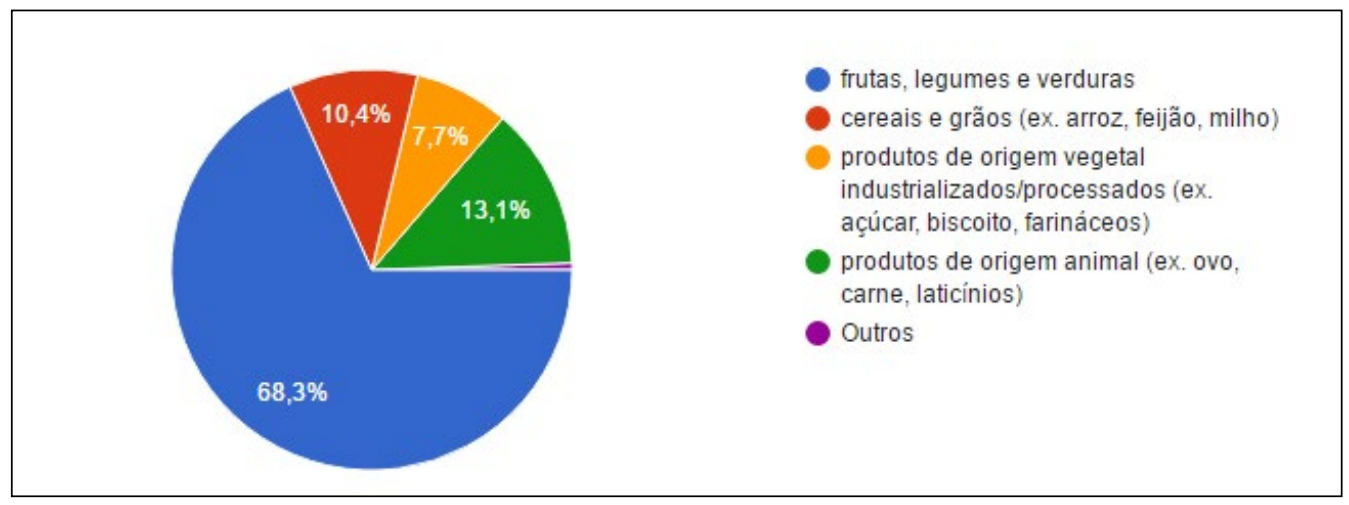

Nota: esta questão foi mensurada por meio que questão de múltipla escolha, sendo que os respondentes só podiam escolher um tipo de alimento orgânico, representando dentre todos estes, o que consome com maior frequência. Foram obtidas 183 respostas válidas.

Através da Figura 3, verifica-se que a 68,3\% dos respondentes afirmam consumir frutas, legumes e verduras com mais frequência dentre os alimentos de origem orgânica, seguido de $13,1 \%$ que afirmam consumir produtos de origem animal, 10,4\% que consomem cereais e grãos e $7,7 \%$ afirmam consumir com mais frequência produtos de origem vegetal industrializados e/ou processados. Frutas, legumes e hortaliças são, na maioria das vezes, produtos orgânicos in natura que têm como característica a ausência da influência da marca no produto, não dependendo de rótulos para serem vendidos no mercado (LOMBARDI; MOORI; SATO; 2008). Os resultados mostram que os produtos orgânicos in natura, também são os mais consumidos na cidade de Santa Maria/RS, indo de encontro aos resultados esperados.

$\mathrm{Na}$ Figura 4, abaixo, evidencia-se o principal motivo que leva os respondentes a consumir alimentos orgânicos.

Figura 4 - Principal motivo que leva os respondentes a consumir alimentos orgânicos

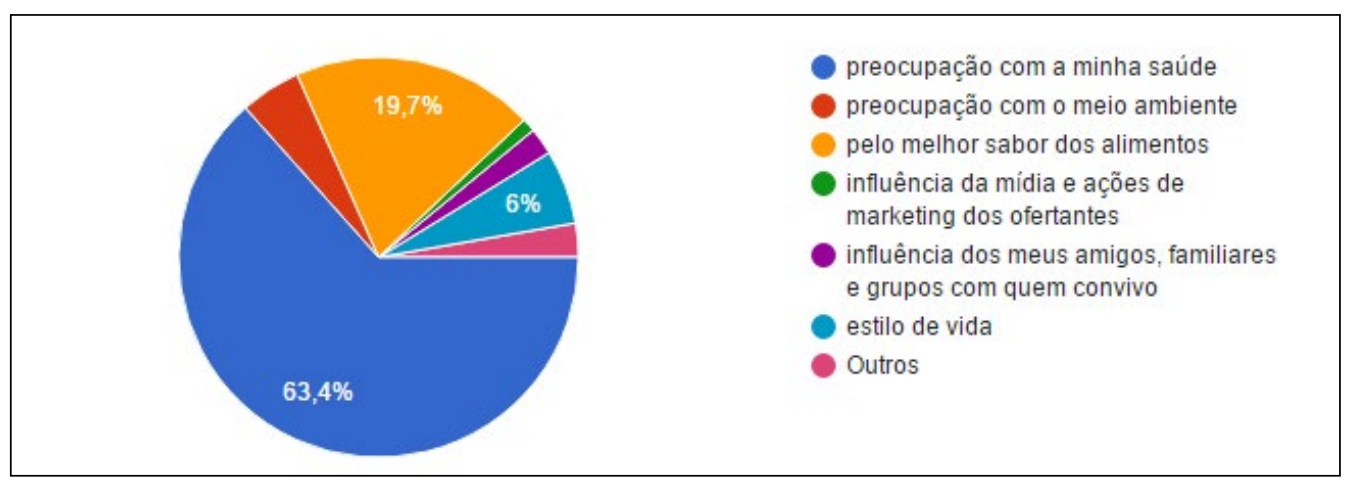

Nota: esta questão foi mensurada por meio que questão de múltipla escolha, sendo que os respondentes só podiam escolher um motivo. Foram obtidas 183 respostas válidas. 
Observou-se que, entre o principal motivo que leva os respondentes a consumirem alimentos orgânicos, em primeiro lugar $(63,4 \%)$ está a questão da preocupação com a saúde. Em segundo lugar, eles consomem orgânicos pelo melhor sabor dos alimentos (19,7\%). A variável saúde foi apontada em diferentes estudos como sendo importante na decisão de escolha do consumidor de alimento orgânico.

$\mathrm{Na}$ pesquisa de Rucinski e Brandenburg (2002), também foi encontrado que 94\% dos consumidores entrevistados indicaram a saúde como principal motivo para consumir produtos orgânicos e 5,9\% dos consumidores afirmou que o sabor do alimento orgânico é melhor, dizendo que os alimentos com agrotóxicos possuem sabor alterado em relação aos orgânicos.

A preocupação com a saúde foi a variável encontrada como mais significativa para a formação de atitudes favoráveis à compra de alimentos orgânicos em diversos estudos, o que mostra que o consumidor está preocupado com o uso de agrotóxicos nos alimentos e seus efeitos prejudiciais à saúde, optando assim, pela alimentação orgânica (BRANDÁO, 2016; PEREIRA et al., 2015; SAMPAIO et al., 2013; HOPPE et al., 2012).

Verifica-se, portanto, que o resultado encontrado pelo presente estudo em relação ao principal motivo que leva os respondentes à consumirem alimentos orgânicos, vai de encontro aos achados dos estudos citados, sendo a preocupação com a saúde o motivo encontrado em primeiro lugar por todos pesquisadores.

A seguir, na Figura 5, pode-se ver a confiança dos respondentes em relação a se os produtos que compram como sendo orgânicos são realmente $100 \%$ orgânicos.

Figura 5 - Confiança dos respondentes se os produtos que compram como sendo orgânicos são realmente $100 \%$ orgânicos

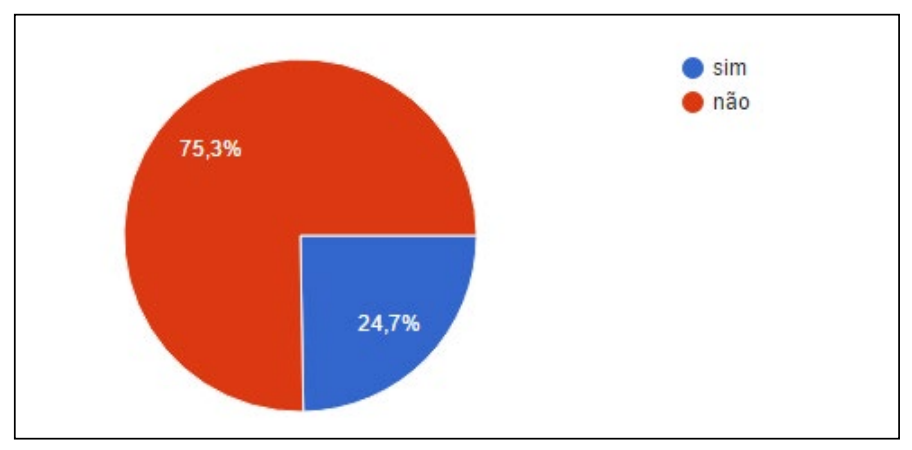

Nota: Foram obtidas 182 respostas válidas.

A Figura 5 traz uma informação extremamente importante acerca deste estudo, mostrando que $75,3 \%$ dos consumidores não têm confiança que o produto que eles adquirem como sendo orgânico realmente seja 100\% orgânico. Em estudo realizado em Manaus/AM, mostrou-se que a identificação dos produtos orgânicos é feita por $74 \% \mathrm{em}$ função da palavra do produtor (DA CRUZ LIMA et al., 2015).

Ormond et al. (2002), explica que na negociação direta entre consumidor e produtor, mesmo quando efetuada através de cooperativas, o produtor dá a garantia ao seu cliente de 
que o alimento foi produzido por processos de manejo orgânico, e este aceita a garantia, por confiar na fonte de informação, influenciado pela proximidade ou pelo ambiente negocial (cooperativas). No Brasil, o estabelecimento de padróes e normas internas para produçáo e comercialização e a criação de selos de garantia para seus produtos (selos de certificação), direcionados principalmente ao mercado interno, teve origem informal através do trabalho desenvolvido por ONGs (associaçóes e cooperativas de produtores e consumidores) (ORMOND et al., 2002).

Em estudo conduzido na cidade de Pelotas/RS por Lovatto et al. (2009), verificouse que os fatores que motivam os consumidores a adquirir seus alimentos na feira são: a responsabilidade com a saúde e o ambiente por parte dos feirantes (36\%), a produçáo sustentável de alimentos (21\%) e confiança nos agricultores que produzem (15\%), mostrando assim que a confiança está em último lugar como fator de compra para alimentos orgânicos, o que pode explicar a grande porcentagem de respondentes do presente estudo que náo confiam plenamente que os alimentos que estejam adquirindo sejam 100\% orgânicos, acreditando apenas na palavra do produtor.

Outro estudo, também realizado em Pelotas/RS por Pereira et al. (2015), mostra que embora os mecanismos de certificação dos produtos orgânicos existam, a confiança do consumidor no alimento orgânico é baseada mais na relação "face-a-face", construída no contato direto com o produtor na feira do que nos selos de certificaçáo e que esta relação constitui parte da ideologia alimentar que estes consumidores adotam. Logo, podese identificar, através do resultado da presente pesquisa, que o mesmo processo em relação à confiança, baseado apenas na palavra do produtor e na relação "face-a-face", também ocorre com os consumidores de alimentos orgânicos da cidade de Santa Maria/RS.

A Figura 6 apresenta o comportamento dos respondentes em relação à sua decisão de compra de alimentos orgânicos.

Figura 6 - Comportamento dos respondentes em relação à sua decisão de compra de alimentos orgânicos

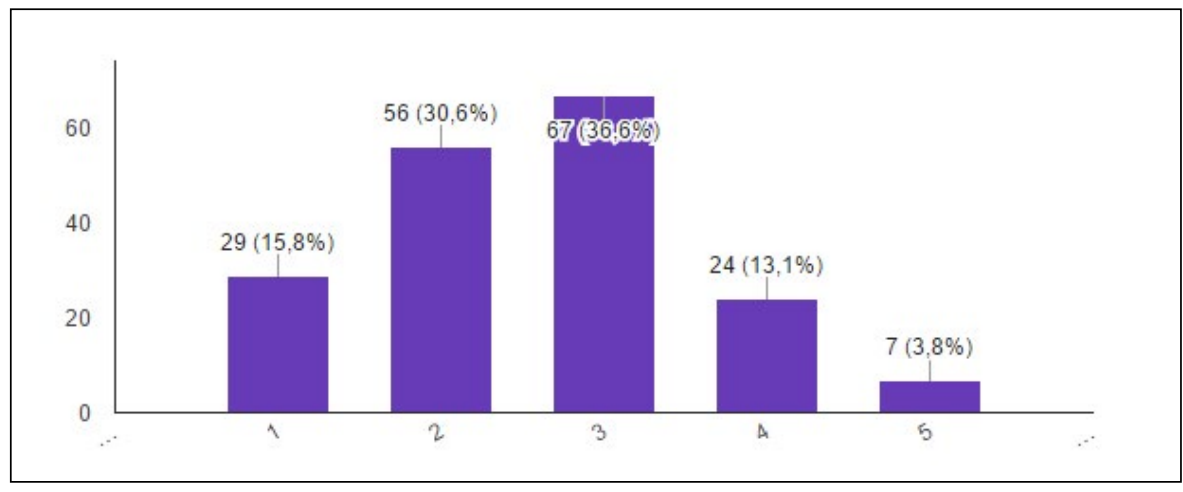

Nota: Esta questáo foi mensurada por meio de escala Likert de 5 pontos, indo de 1 (São 100\% compras PLANEJADAS) até 5 (São 100\% compras POR IMPULSO). Foram obtidas 183 respostas válidas. 
Através da Figura 6, pode-se notar que as compras de alimentos orgânicos tendem a ser mais planejadas do que por impulso. Em uma pesquisa desenvolvida com consumidores de tomates orgânicos na cidade de Porto Alegre/RS, Hoppe et al. (2012) aplicaram a Teoria do Comportamento Planejado (TCP), para compreender melhor o modo como esses consumidores planejam suas compras, verificando que as atitudes e a disponibilidade têm influência significativa na intenção de consumo, logo, quanto mais favorável a atitude e quanto maior a disponibilidade do produto, maior é a intenção de compra de tomates orgânicos dos consumidores pesquisados. Evidencia-se, portanto, que assim como no estudo de Hoppe et al. (2012), os consumidores de alimentos orgânicos da cidade de Santa Maria/RS, também tendem a desenvolver mais compras planejadas do que por impulso, devido à disponibilidade deste tipo de produto.

Finalmente, na Figura 7, evidencia-se, em relação aos respondentes que afirmaram nunca consumir alimentos orgânicos, o principal motivo do comportamento de não consumir alimentos orgânicos.

Figura 7 - Principal motivo do comportamento de não consumir alimentos orgânicos

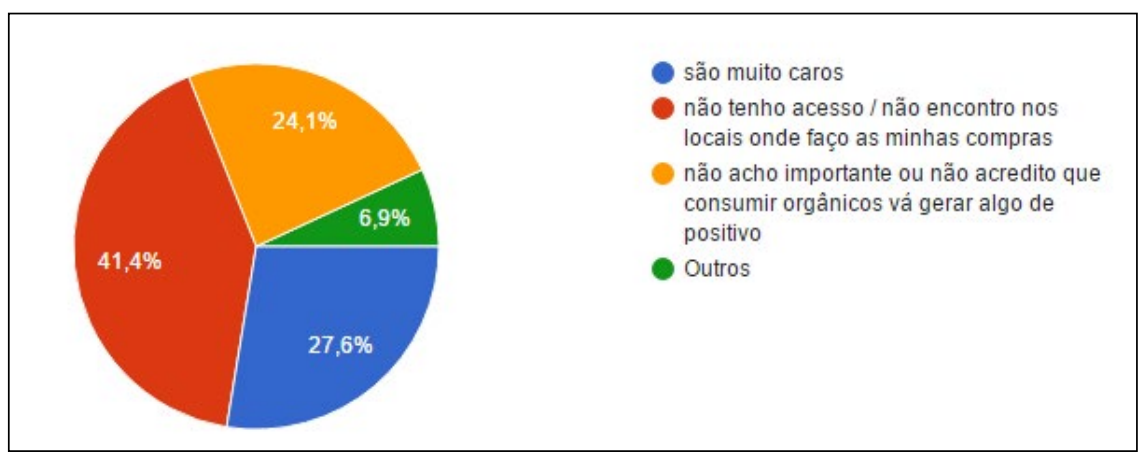

Nota: Esta questão se aplica a todos os respondentes que marcaram 1 (nunca consumo alimentos orgânicos) na questão 1, mostrada da Figura 1. Foram obtidas 29 respostas válidas.

Como mostra a Figura 7, os respondentes que afirmaram nunca consumir alimentos orgânicos, justificaram em sua maioria, como o principal motivo para esse comportamento a falta de acesso aos mesmos (41,4\%), seguido do preço muito caro $(27,6 \%)$, e $24,1 \%$ não consideram importante ou não acreditam que o consumo de orgânicos vá gerar algo de positivo. Conforme o resultado encontrado por Braga Junior, Neto e Moraes (2014), mesmo que o consumidor demonstre preocupação com o meio ambiente, no varejo convencional ele não possui o hábito de adquirir produtos orgânicos, mas sim o de manter a sua rotina de compras. Verifica-se que no Brasil há pouca oferta para atender a demanda por produtos orgânicos, o que faz com que o consumidor, muitas vezes, não compre este produto porque não lhe é ofertado em quantidade suficiente, por um preço acessível e nos locais em que ele frequentemente compra (BUZIN, 2016). 


\section{Conclusóes}

No intuito de adotar um estilo de vida mais saudável, muitas pessoas vêm optando por substituir os alimentos convencionais pelos alimentos orgânicos, mostrando uma maior consciência em relaçáo aos cuidados com a saúde e o meio ambiente, o que fez crescer a demanda por produtos orgânicos em todo o mundo nas últimas décadas, bem como a sua divulgaçáo junto à população. Neste contexto, o presente trabalho teve como objetivo, identificar o perfil dos consumidores produtos orgânicos da cidade de Santa Maria/RS.

$\mathrm{O}$ estudo encontrou um perfil de respondentes que dizem consumir alimentos orgânicos de maioria do gênero feminino, com alta escolaridade, solteiro e sem filhos. Esse grupo, por ter maior poder aquisitivo, maior escolaridade, não precisar gastar com cônjuges e/ou filhos, o que explica poderem consumir alimentos orgânicos, que são, na maioria das vezes, mais caros e de difícil acesso, pois não estão à venda em qualquer lugar, precisando ter uma compra planejada. Além disso, o gênero feminino possivelmente possui maior preocupação com a saúde e boa forma, o que teria potencial para explicar uma maior procura por alimentos livre dos agrotóxicos, e orgânicos, que em sua maioria, são constituídos por alimentos in natura.

A preocupação com a saúde é o principal motivo para o consumo de orgânicos, mas a maioria não tem total confiança de que os alimentos que compram como orgânicos o sejam $100 \%$. A saúde têm sido fator cada vez de maior atenção em todo o mundo, o que fez surgir uma nova consciência alimentar, em um movimento contra o fast-food e também do surgimento de um consumo verde e sustentável, que ainda não é muito estimulado por muitos governos. Os respondentes que não consomem orgânicos afirmam como principal motivo a falta de acesso, o que mostra que há uma demanda no mercado por esses produtos, cuja oferta é muito baixa em relação ao alimento convencional. É possível que uma parcela considerável do mercado consumidor tenha interesse em consumir orgânicos ao invés dos alimentos convencionais, mas um dos limitadores para tal consumo pode ser a falta de acesso já que os orgânicos ainda são caros. Isso pode fazer com que muitos consumidores permaneçam optando por consumir alimentos convencionais para manter o orçamento familiar.

Uma das principais limitaçóes do estudo foi em relação à amostra, que constituiuse, em parte, de estudantes de uma Instituição de Ensino Superior localizada na cidade de Santa Maria-RS, o que pode explicar o grande índice de estudantes do superior incompleto no perfil dos respondentes. Também parte considerável das respostas obtidas deu-se por meio do Facebook, em grupos de consumidores de produtos orgânicos e em geral, não sendo estritamente limitada a pessoas que se dizem consumidoras de produtos orgânicos. Assim, sugerem-se a condução de novos estudos ampliando o questionário, aplicando-o apenas com pessoas que se dizem consumidoras de produtos orgânicos, em feiras e comércio local destes produtos, bem como ver o perfil dos consumidores de produtos orgânicos entre vegetarianos e veganos, expandindo ainda mais as possibilidades de estudos sobre o tema. 


\section{Referências}

ARAÚJO, D. F. S.; PAIVA, M. do S. D.; FILGUEIRA, J. M. Orgânicos: expansão de mercado e certificação. Holos, ano 23, v. 3, 2007.

BABBIE, E. Métodos de pesquisas de survey. Editora da UFMG, 1999.

BARBOSA, S. de C.; MATTEUCCI, M. B. de A.; LEANDRO, W. M.; LEITE, A. F.; CAVALCANTE, E. L. S.; ALMEIDA, G. Q. E. de. Perfil do consumidor e oscilações de preços de produtos agroecológicos. Pesquisa Agropecuária Tropical, Goiânia, v. 41, n. 4, p. 602-609, out./dez. 2011.

BRAGA JUNIOR, S. S.; NETO, A. R. V.; MORAES, N. R. Atributos de Estilo de Vida do Consumidor Relacionados ao Consumo de Produtos Orgânicos no Varejo Especializado. REMark, v. 13, n. 5, p. 36, 2014.

BRANDÃO, W. A. Consumo saudável: uma análise do comportamento do consumidor no contexto dos alimentos orgânicos. Dissertação - UFPB/CCSA, Programa de PósGraduação em Administração, João Pessoa, 2016.

BUAINAIN, A. M.; BATALHA, M. O. Agronegócios: cadeia produtiva de produtos orgânicos. Brasília, DF: IICA/MAPA/SPA, 2007.

BUZIN, E. J. W. K. Mercado de produtos orgânicos em Goiânia: venda direta. Tese Universidade Federal de Goiás, Escola de Agronomia (EA), Programa de Pós-Graduação em Agronomia, Goiânia, 2016.

CAMPANHOLA, C.; VALARINI, P. J. Cadernos de Ciência \& Tecnologia, Brasília, v. 18, n. 3, p. 69-101, set./dez. 2001.

CERVO, A. L.; BERVIAN, P. A. Metodologia científica. 4. ed. São Paulo: Makron Books, 1996.

CHURCHILL Jr, G. A.; PETER, J. P. Marketing: criando valor para os clientes. 3. ed. São Paulo: Saraiva, 2012.

COELHO, C. N. A expansão e o potencial do mercado mundial de produtos orgânicos. Revista de Política Agrícola, ano 10, n. 2, abr/maio/jun, 2001.

CRESWELL, J. W. Projeto de pesquisa: métodos qualitativo, quantitativo e misto. 3. ed. Porto Alegre: Artmed, 2010.

DA CRUZ LIMA, P. D. F.; DE LIMA, A. M. M.; DE CASTRO, S. M. V.; GOMES; M. D. V. C. N. O consumo de alimentos orgânicos na cidade de Manaus (AM): o comércio de produtos e a sustentabilidade do setor. Revista Verde de Agroecologia e Desenvolvimento Sustentável, v. 10, n. 1, p. 120-127, 2015. 
DAROLT, M. R. Agricultura Orgânica: inventando o futuro. Londrina: IAPAR, 2002.

ENGEL, J. F.; BLACKWELL, R. D.; MINIARD, P. W. Comportamento do consumidor. 8. ed. Rio de Janeiro: LTC, 2000.

GALHANONE, R. F. Atitudes, emoçóes, e comportamento de compra: um estudo com consumidores de produtos de luxo ou sofisticados. Dissertaçáo - Curso de Mestrado do Programa de Pós-Graduação em Administração, Universidade de São Paulo, 2008.

GIGLIO, E. M. O comportamento do consumidor. 2. ed. rev. ampl. São Paulo: Pioneira, 2003.

GIL, A. C. Como elaborar projetos de pesquisa. 4. ed. São Paulo: Atlas, 2002.

HOPPE, A.; BARCELLOS, M. D. de; VIEIRA, L. M.; MATOS, C. A. de.

Comportamento do consumidor de produtos orgânicos: uma aplicação da teoria do comportamento planejado. BASE - Revista de Administraçáo e Contabilidade da Unisinos, São Leopoldo, v. 9, n. 2, p. 174-188, abr./jun. 2012.

IBDAIWI, T. K. R. Determinação das características de preferência dos alunos na escolha de uma instituição de ensino superior privada na cidade de Santa Maria - RS. Dissertaçáo - Curso de Mestrado do Programa de Pós-Graduação em Engenharia de Produção, UFSM, Santa Maria, 2009.

IBGE: Instituto brasileiro de geografia e estatística. Disponível em: <http://www.cidades. ibge.gov.br/painel/painel.php?lang=\&codmun=431690\&search=rio-grande-do-sul|santamaria|infograficos:-dados-gerais-do-municipio> Acesso em: 12 de maio de 2016.

KARSAKLIAN, E. Comportamento do consumidor. 2. ed. 5. reimpr. São Paulo: Atlas: 2011.

KOTLER, P.; KELLER, K. L. Administração de marketing. 14. ed. São Paulo: Pearson, 2012.

KRISCHKE, P. J.; TOMIELLO, N. O comportamento de compra dos consumidores de alimentos orgânicos: um estudo exploratório. Cadernos de Pesquisa Interdisciplinar em Ciências Humanas, v. 10, n. 96, p. 27-43, 2009.

LEME, R. Aplicação prática de gestão por pessoas por competências. São Paulo: Atlas, 2008.

LOMBARDI, M. S.; MOORI, R. G.; SATO, G. S. Um estudo exploratório dos fatores relevantes na decisão de compra de produtos orgânicos. Revista de Administraçáo Mackenzie, ano 5, n. 1, p. 13-34, 2004. 
LOVATTO, P., NASCIMENTO, S. G., DA SILVA ANDERSSON, F., BEZERRA, A. Caracterização do consumo em uma feira livre de base ecológica do Município de Pelotas, RS, Brasil. Revista Brasileira de Agroecologia, v. 4, n. 2, 2009.

MARCONI, M. de A.; LAKATOS, E. M. Fundamento de metodologia científica. 7. ed. São Paulo: Atlas, 2010.

MATTEI, D.; MACHADO, M.; OLIVEIRA, P. A. de. Comportamento do consumidor: fatores que influenciam no processo de decisão de compra dos consumidores finais.

Maringá Management: Revista de Ciências Empresariais, v. 3, n. 2, p. 27-37, jul./dez. 2006.

MICHEL, M. H. Metodologia e pesquisa científica em ciências sociais. São Paulo: Atlas, 2005.

MIRANDA, L. Cresce a variedade de alimentos mais saudáveis. O Estado de Sáo Paulo, Sáo Paulo, p. A11, 19 nov. 2001. Biotecnologia.

MOWEN, J. C.; MINOR, M. S. Comportamento do consumidor. São Paulo: Prentice Hall, 2003.

ORMOND, J. G. P.; PAULA, S. R. L.; FILHO, P. F.; ROCHA, L. T. M. da. Agricultura Orgânica: Quando o passado é futuro. BNDES Setorial. Rio de Janeiro, n. 15, p. 3-34, mar. 2002.

PEREIRA, M. C.; MÜller, C. R.; RODRIGUES, F. S. A.; MOUTINHO, A. B. A.; RODRIGUES, K. L.; BOTELHO, F. T. Mudança no perfil sociodemográfico de consumidores de produtos orgânicos. Revista Ciência \& Saúde Coletiva, v. 20, n. 9, 2015 .

PINHEIRO, R. M. Comportamento do consumidor e pesquisa de mercado. 3 . ed. Rio de Janeiro: FGV, 2006.

PINHEIRO, R. M., CASTRO, G. C. de; SILVA, Helder H.; NUNES, José M. G.

Comportamento do Consumidor. Rio de Janeiro: Editora FGV, 2011.

RODRIGUES, M. A.; JUPI, V. da S. O comportamento do consumidor: fatores que influenciam em sua decisão de compra. Revista de Administraçáo Nobel, n. 3, p. 59-70, jan./jun. 2004.

RUCINSKI, J.; BRADENBURG, A. Consumidores de alimentos orgânicos em Curitiba. I Encontro da Associação Nacional de Pós-Graduação em Ambiente e Sociedade, nov. 2008. Anais... Indaiatuba-SP: ANPPAS, 2002.

SAMARA, B. S.; BARROS, J. C. de. Pesquisa de marketing: conceitos e metodologia. 3. ed. São Paulo: Prentice Hall, 2002. 
SAMARA, B. S.; MORSCH, M. A. Comportamento do consumidor: conceitos e casos. São Paulo, SP: Pearson Prentice Hall, 2005.

SAMPAIO, D. de O.; GOSLING, M.; FAGUNDES, A. F. A. F.; VELOSO E SOUSA, C. Uma análise da produção acadêmica brasileira sobre o comportamento do consumidor de alimento orgânico entre 1997 a 2011. REAd, Porto Alegre, ed. 76, n. 3, p. 620-645, set./dez. 2013.

SANTOS, G. C. dos; MONTEIRO, M. Sistema orgânico de produção de alimentos. Alimentos e Nutriçáo, Araraquara, v. 15, n. 1, p. 73-86, 2004.

SANTOS, G. E. de O. Cálculo amostral: calculadora on-line. Disponível em: <http:// www.calculoamostral.vai.la>. Acesso em: 12 maio de 2016

SCHIFFMAN, L. G.; KANUK, L. L. Comportamento do consumidor. Rio de Janeiro: LTC, 2000.

SHETH, J. N.; MITTAL, B.; NEWMAN, B. I. Comportamento do cliente: indo além do comportamento do consumidor. São Paulo: Atlas, 2001.

SIQUEIRA, M. A. da S. Monografias e teses: das normas técnicas ao projeto de pesquisa. 2. ed. Brasília: Consulex, 2013.

SOLOMON, M. R. O comportamento do consumidor: comprando, possuindo e sendo. 5. ed., Porto Alegre: Bookman, 2002.

ZIKMUND, W. G. Princípios da pesquisa de marketing. São Paulo: Pioneira Thomson Learning, 2006.

ZUIN, L. F. S.; QUEIROZ, T. R. Agronegócios: gestão e inovação. São Paulo: Saraiva, 2006. 